\title{
Coletivizando saberes: (re)construção da memória ambiental de moradores da cidade de Botucatu
}

\author{
Carolina Delgado de Carvalho ${ }^{1}$ \\ Marilia Freitas de Campos Tozoni-Reis ${ }^{2}$
}

Resumo: Este trabalho apresenta 0 resgate da memória ambiental de moradores idosos da cidade de Botucatu (SP) através da metodologia da História O ral de Vida. Seu objetivo é contribuir para o levantamento e valonização da história da cidade, gerando conhecimentos para propostas de sensibilização e ações de E ducação Ambiental nos espaços urbano e rural do município. Observaram-se nos relatos a percepção da crescente separação homem-natureza e a adesão a processos insustentáveis de desenvolvimento, o que gerou sérios problemas socioambientais.

Palavras-chave: Memória ambiental, História oral de vida, Ambiente urbano.

Abstract: This paper presents a rescue of the environmental memory of inhabitants of the city of Botucatu (São Paulo) through Life O ral History methodology. Its objective is to contribute with the survey and valuation of the history of this city, generating knowledge for awareness-raising proposals and Environmental Education actions in rural and urban spaces in the municipal district of Botucatu. We could observe an increasing process of man-nature separation and the adherence to unsustainable development processes, what has generated serious socioenvironmental problems.

Keywords: Environmental memory, Life oral history, Urban environment.

\section{Introdução}

A problemática ambiental tornou-se motivo de preocupação para diversos setores da sociedade por vivermos, desde a segunda metade do século XX, uma crise ambiental sem precedentes na história

1 Bióloga e mestre em Agroecologia e Desenvolvimento Rural - Professora na Universidade Católica Dom Bosco (Campo Grande - MS). Contatos: Av. Tamandaré, 4743 - Jd. Seminário - Campo Grande - MS - CEP: 79117-010 ou purcera_bio@yahoo.com.br

2 Pedagoga, Mestre e D outora em Educação. Professora do D epto de Educação / IB / UNE SP (Botucatu) e do Programa de Pós-graduação em Educação para a Ciência da UNESP (Bauru). Contato: mariliaedu@ ibb.unesp.br 
da humanidade. No contexto da reorientação da ação humana em sua relação com 0 ambiente, a Educação Ambiental surge não só como necessidade, mas também como esperança para 0 enfrentamento dessa crise (GRÜN, 1996). Ela esteve presente desde o início dessa preocupação mais sistemática com 0 ambiente, mas o conceito de Educação Ambiental foi mudando ao longo do tempo. Inicialmente relacionado à ideia de natureza e o modo de percebê-la, tal conceito tem acentuado a necessidade de levarmos em conta os vários aspectos que interferem nas situações ambientais, incorporando as dimensões socioeconômica, política, cultural e histórica de uma população (VIDÁGUA, 2004). Assim, a educação ambiental tomou-se uma dimensão da educação.

Partindo da ideia de que a Educação é "o ato de produzir direta e intencionalmente em cada indivíduo singular a humanidade que é, histórica e coletivamente, produzida pelo conjunto de homens" (SAVIANI, 1994, p. 24) e de que "nenhuma ação educativa pode prescindir de uma reflexão sobre o homem e de uma análise sobre suas condições culturais" (FREIRE, 1979, p. 28), pensemos na Educação Ambiental como uma prática educativa que tem por objetivos a emancipação do indivíduo e sua sensibilização para as questões socioambientais.

As práticas de Educação Ambiental, nessa perspectiva, nos fazem refletir sobre a importância de conhecermos o ambiente em que vivemos, inclusive em sua dimensão histórica e cultural. Essas práticas devem tratar de questões globais críticas, suas causas e inter-relações em uma perspectiva sistêmica, em seu contexto local e global.

A Educação Ambiental assim concebida direciona-se para a compreensão e busca da superação das causas estruturais dos problemas ambientais por meio da ação coletiva e organizada. Segundo essa percepção, a leitura da problemática ambiental deve se realizar sob a ótica da complexidade do meio social, e o processo educativo deve pautar-se em uma postura dialógica, problematizadora e comprometida com transformações estruturais da sociedade, de cunho emancipatório (LOUREIRO, 2004). 
Com essa compreensão sobre a Educação Ambiental, este artigo apresenta os resultados de um trabalho de pesquisa realizado sob a forma de um levantamento histórico - em fontes não oficiais - sobre 0 ambiente natural e construído na cidade de Botucatu (SP). 0 resgate da memória de moradores idosos da cidade, de suas lembranças sobre 0 ambiente social, rural e urbano, foi a fonte da pesquisa, cujo objetivo foi contribuir para a valorização da história da cidade nas práticas de Educação Ambiental, produzindo conhecimentos para suas propostas educativas e ações ambientais, tanto no espaço urbano como no rural. Dessa forma, o problema de pesquisa que norteou este estudo foi "a (re)construção da história do ambiente social e natural de Botucatu SP pelas lembranças dos seus moradores idosos".

\section{Metodologia}

Considerando a importância da vivência dos moradores para 0 resgate da história do ambiente e suas transformações e tendo em vista a sistematização da memória ambiental do ambiente urbano estudado, utilizamos a metodologia qualitativa da História O ral de Vida (MEIHY, 1996; MINAYO, 1994; VIERTLER, 2002). Essa modalidade de pesquisa histórica "vem se impor como contra-história, operando uma inversão historiográfica radical, tanto do ponto de vista dos objetos como dos métodos. História vista de baixo, história do local e do comunitário, dos humildes e dos sem-história, tira do esquecimento aquilo que a história oficial sepultou" (FERREIRA, 1994). Além disso, definimos que nossos entrevistados seriam pessoas idosas residentes na cidade, pois "os velhos são a fonte de onde jorra a essência da cultura, ponte onde o passado se conserva e o presente se prepara. Sua função social, que é lembrar e aconselhar, unir o começo e o fim, ligando o que foi e o por vir, deve ser resgatada" (BOSI, 1983).

Por outro lado, muito se tem discutido sobre a necessidade de escrever a história dos oprimidos, dos vencidos (ENG UITA, 1989), daqueles para os quais, além de tudo o mais, tem sido negado o registro de sua história. A escassez de fontes que relatam a história desses sujeitos sociais tem levado muitos estudiosos a buscar fontes 
alternativas aos tradicionais documentos históricos. Assim, pudemos perceber como a memória dos velhos pode ser interessante fonte de investigação das modificações socioambientais que buscamos compreender.

Com essas preocupações e considerando a definição formal de pessoas idosas como aquelas que têm 60 anos ou mais, foram entrevistadas 16 pessoas com idades entre 60 e 92 anos que vivem no município de Botucatu. Os primeiros contatos foram feitos com integrantes de um grupo de convivência da terceira idade da cidade e essas pessoas foram indicando outras, de modo a formar uma "rede" de entrevistados que preenchiam os pré-requisitos necessários ao estudo: ter mais de 60 anos e ter morado grande parte desses anos na cidade de Botucatu.

As entrevistas foram realizadas individualmente ou em grupos de duas ou três pessoas, gravadas em fita cassete e transcritas na íntegra. Essas entrevistas seguiram a orientação de entrevistas semiestruturadas, isto é, aquelas que partem de um roteiro predeterminado, mas permitem e estimulam 0 aproveitamento de outros temas e assuntos que vão sendo redefinidos no seu decorrer, segundo a metodologia sugerida por Meihy (1996).

Seguiu-se à coleta de dados pelas entrevistas semiestruturadas a etapa de organização e análise dos dados. É interessante observar que, num primeiro momento, organizamos esses dados da forma mais convencional em uma pesquisa de campo como proposto por Minayo (1994): em categorias. Foram 12 as categorias definidas que seriam analisadas e discutidas com base em referenciais teóricos: transporte, lazer, clima, saúde, lendas, ambiente rural e urbano, atividades econômicas, violência, educação, cidade antiga, cultura, recursos. Porém, ao lidarmos com as categorias e seus conteúdos, verificamos que a riqueza dos relatos não conseguia ser expressa nessa forma de organização dos dados. Percebemos que, nessa forma, o trabalho sairia empobrecido, pois essa metodologia exige muitos recortes nas falas, retirando a riqueza das entrelinhas, das pausas reveladoras de sentimentos e percepções mais aprofundadas a respeito das transformações do ambiente na cidade e no campo. Inspiradas nos 
estudos das narrativas, tanto naqueles fundamentados na hermenêutica (CARVALHO, 2002) quanto naqueles fundamentados nas representações sociais (REIGOTA, 1999), criamos, então, uma única história para a apresentação dos resultados, isto é, apresentamos os dados coletados como se eles emergissem de uma narração coletiva. Todos esses referenciais metodológicos têm em comum, e isso nos inspirou particularmente, a abordagem crítica da Educação Ambiental e a necessidade de superação da razão instrumental nos trabalhos acadêmicos.

O s resultados apresentados em forma de história coletiva, com muitas imagens fornecidas pelos entrevistados em forma de fotografias, resultaram, no estudo que deu origem a este artigo, em sessenta e duas páginas. Para este artigo, a história coletiva foi sintetizada, abordando-se os pontos mais importantes no que diz respeito às transformações ambientais da cidade de Botucatu, e discutida naquilo que revela como ponto fundamental das transformações: 0 modelo de desenvolvimento econômico vivido.

\section{A histónia coletiva}

Botucatu começou lá no Lavapés, um riozinho de água "limpa, limpa, limpa". No momento em que foi fundada, a cidade era "boca de sertão", quer dizer, porta para o oeste, o oeste de São Paulo. 0 que caracterizou o início da história moderna de todo o estado de São Paulo foi a conquista do oeste, assim como ocorreu para o Brasil todo. Especificamente para São Paulo, os colonizadores foram conquistando o litoral e depois foram subindo a serra, até que foi criado o estado de São Paulo em meados do século XVI. Em seguida, o que identificou 0 chamado progresso foi a conquista do oeste.

$\mathrm{Na}$ história de Botucatu, tivemos um tempo de ignorância muito grande, banditismo mesmo, lá pela metade de 1800, já que, por ser "boca de sertão", a lei praticamente não existia. A lei vigorava na cidade de São Paulo e em outras cidades maiores do Brasil. À medida que Botucatu foi crescendo, também cresceu o estado para o oeste e a cidade foi ficando mais civilizada, principalmente por dois fatores: a 
chegada da lei e o progresso. A lei chegava através do delegado de polícia, da cadeia, juiz, instalação da comarca, etc.; o progresso, com 0 aparecimento do automóvel, da ferrovia, etc.

D esde 0 início da cidade, o linguajar - assim como por todo 0 interior - era característico: falava-se 0 " $\mathrm{r}$ " puxado. 0 contato do botucatuense com a natureza era maior. Botucatu era uma cidade menor e mais simples, mas o progresso foi aparecendo e tudo foi sendo modificado. Um automóvel, por exemplo, era uma novidade. Alguns compravam carros importados porque ainda não existia fábrica de automóveis no Brasil. Para comprar um Ford 46, por exemplo, tinha-se que entrar na fila e ficar esperando o carro chegar. Q uando chegava um Ford 46, já era, pro exemplo, maio de 1947, e se fazia uma festa! Nessa época, a cidade tinha 25 ou 30 automóveis. Tudo o que significava tecnologia, avanço e progresso demorava bastante para chegar.

A agressão ao meio ambiente existiu desde 0 início da história da cidade, mas durante muito tempo foi bem menor do que é hoje. Essa agressão foi crescendo com o progresso tecnológico. Q uando ele ainda não havia chegado até onde chegou, quando não existiam a ferrovia e a rodovia e fazia-se agricultura e pecuária em menor escala, essa agressão era bem menor. Hoje, na agricultura, por exemplo, são usados defensivos agrícolas, tratores, máquinas, eletricidade, etc. 0 homem hoje tem um poderio enorme, a tecnologia nas mãos, mas tudo isso agride frontalmente 0 meio ambiente.

A cidade teve origem na Rua do Sapo, hoje Rua Rangel Pestana. Era chamada assim porque na beira do rio os sapos faziam "uma orquestra". A Rua Amando, a Rangel Pestana e a Curuzu são as ruas mais velhas da cidade. Depois veio a Rua João Passos, em 1955. Nessa época, a cidade terminava logo abaixo do Colégio Santa Marcelina: "ali já não havia quase nada". A principal rua da cidade sempre foi a Rua Amando (Amando de Barros). A Rua Curuzu foi o reduto dos imigrantes italianos: foram os primeiros comerciantes e negociantes. A Rua Amando ia do jardim do Paratodos até a Igreja de São Benedito. Na Avenida Santana, no lugar da atual catedral, era o campo de futebol dos seminaristas. Depois construíram a catedral velha, a primeira. Mais tarde construíram a catedral que existe hoje: "Para mim foi bastante 
gratificante porque a primeira turma de professores que se formou no ano de 43, da qual eu fazia parte, recebeu uma missa, foi a primeira missa celebrada na catedral nova, no dia 12 de dezembro de 1943".

0 jardim em frente à catedral foi projetado no "estilo francês", as mudas foram trazidas da Europa por Amando de Barros: "Muitas flores, muitos jardins, era muito bonito". Metade dele foi destruído: "Graças a Deus a outra metade eles preservaram, ninguém desmanchou, não quebraram, não apareceu ninguém querendo modernizar, felizmente, porque o lá de baixo...". A cidade tinha praças lindas. A Praça do Bosque, por exemplo, foi muito linda. A Praça Coronel Moura, em frente ao Paratodos, era um jardim maravilhoso! Lindo! Quando não tinha televisão, os casais iam passear no bosque e levavam os filhos menores. Os moços ficavam namorando nessas praças. Crianças brincavam.

A Praça Coronel Moura hoje é toda cimentada: "Uma judiação!". D estruíram a arquitetura do jardim antigo para fazer tudo aquilo: “É um pecado!". Era tudo muito bem plantado: figueiras e outras árvores antigas. Um prefeito resolveu reformar, em nome do progresso, e destruiu tudo. O progresso veio e as coisas foram se modificando. A cidade era diferente, mais simples. As pessoas se conheciam. Podíamos passear, brincar, sair na rua, conhecíamos todo mundo. Brincávamos muito de pular corda. É engraçado que agora não vemos as crianças na rua: "Naquele tempo na cidade era uma criançada...".

O crescimento da cidade de Botucatu não foi planejado, permitiu a criação desordenada de bairros afastados, surgindo então os problemas, como os transportes, por exemplo: problemas da urbanização que até hoje não foram convenientemente resolvidos. Isso se vê no Parque Marajoara, no Jardim Brasil e em muitos outros bairros onde a distância do centro da cidade e o desequilíbrio social são muito grandes.

As fazendas de café foram importantes para o desenvolvimento de Botucatu. Eram muitas, cada uma delas com 10-15 colonos. Esses colonos precisavam de alimentação, calçados, gêneros de primeira necessidade, que iam procurar na cidade, pois eles achavam ter preços 
melhores. Botucatu era uma cidade com comércio forte, chegou a ter oito bancos, pois aqui corria bastante dinheiro. No entanto, Botucatu nunca foi muito forte na agricultura e na pecuária. A cidade tinha um comércio forte, muitos bancos: "Por aqui corria muito dinheiro".

No final da década de 40 e começo de 50, Botucatu era uma das cidades mais importantes do estado. No entanto, não era toda calçada, não tinha serviços de água, esgoto e eletricidade para todos. Havia muitas chácaras e fazendas no entorno, existia muito mais verde do que hoje. 0 contato da população urbana com 0 meio rural era mais intenso. Famílias passeavam no fim de semana em chácaras, sítios, fazendas e 0 contato das crianças com 0 meio rural era muito maior: conheciam plantação de café, mandioca, milho, horta, chiqueiro, curral e estrebaria. Botucatu foi uma cidade pequena até que cortou os laços com a zona rural. Mas hoje a zona rural tem benefícios da tecnologia, criando novas pontes com a zona urbana. Um sítio hoje tem televisão e vários outros recursos.

Botucatu tem dois tipos de terra. A maior parte é o Arenito Bauru, um arenito com mistura de calcário, mais duro que 0 arenito comum e que resulta numa terra escura, razoavelmente apropriada para a plantação de café. O Arenito Botucatu, por outro lado, embora em menor área, é o "daqueles campos com arvorezinhas tortas, campo sujo ou cerrado: este não se presta para o café, só para a pecuária". Há também manchas de terra roxa, com diabásio e basalto, que é a Formação Serra Geral. D escendo a Serra, há cortes no relevo aflorando derrame de lava, que forma o diabásio e 0 basalto. Nessas manchas de terra roxa foi plantado café, uma cultura menor na agricultura da cidade.

A destruição da lavoura fez com que essas pessoas que estavam estabilizadas no campo, que tinham suas casas, suas famílias, seus divertimentos (aos sábados iam aos bailes e festas religiosas), se mudassem para a cidade. A expulsão da população do campo deu-se sem as condições de trabalho, emprego e moradia na cidade. Foi o que aconteceu em Botucatu: 0 crescimento da cidade não foi planejado, houve a criação desordenada de bairros afastados, criando problemas 
de transporte e urbanismo que persistem até hoje. É o que vemos nos bairros afastados do centro, onde o desequilíbrio social é muito grande.

D urante algum tempo, achava-se que quem degradava, quem poluía era a população mais pobre. Mas não é: "Gente de nível universitário também polui". Os sacos de lixo, por exemplo, são jogados nos barrancos. Esse desequilíbrio ambiental pode ser sentido no aumento da poluição da cidade e dos rios. É difícil dizer se as pessoas poluíam menos ou se a população era menor. Antigamente, não havia tanto plástico, as pessoas faziam passeios e levavam lanches em saquinhos de papel e garrafas de vidro. Hoje, o mundo foi invadido pelo plástico, pelas garrafas de refrigerante e pelas latinhas. Tudo é feito de plástico: veja a quantidade dele que é encontrada nas ruas e nos rios. 0 aumento da população aumentou o lixo, mas as diferentes formas de consumo são também responsáveis por isso. Até pouco tempo atrás, as fraldas descartáveis não existiam, tínhamos que lavar e passar para reutilizar. Esse "progresso" nós copiamos dos Estados Unidos, que mandaram essa cultura para cá: fraldas, garrafas, tudo descartável, favorecendo o aumento da poluição.

Hoje os rios da cidade estão praticamente mortos. Um rio importante para Botucatu, o Rio Lavapés, tinha a água limpa, peixinhos, uma gracinha! Víamos o fundo de areia do rio porque ele era rasinho, pegávamos essa areia para arear panelas. Quando faltava água encanada, íamos lavar roupa nas águas do Rio Lavapés e púnhamos para quarar nas pedras das margens. Usávamos sabão de pedra feito em casa, com restos de óleo e gordura utilizados na cozinha. Esse rio tinha dois moinhos geradores de farinha. Havia intensa vegetação nas suas margens, tudo natural. A natureza aqui era linda! As crianças escapavam para brincar além do Lavapés, era tudo mato. Os meninos, principalmente, conheciam toda essa área das imediações de Botucatu, brincando muito nesses lugares. Hoje o rio está poluído.

As crianças iam para a escola. Fazia muito frio no inverno e a névoa da manhã rachava os lábios das crianças. A escola primária funcionava naquele prédio ao lado da catedral, e 0 ensino já era muito importante na cidade. 
As crianças da época se divertiam com brincadeiras que elas mesmas inventavam: teatrinho de bonecos, finca-finca, bolinhas de pano ou meia, peões, pular corda, carrinho de rolimã, papagaio, pegar fruta no quintal dos outros, caçar passarinho, jogar futebol em terrenos vazios da cidade, carrinhos de marcenaria e outros brinquedos que elas mesmas faziam. Hoje só se brinca com brinquedo moderno, com tecnologia. Mas naquela época era divertido, porque a meninada brincava toda junta. Hoje parece que o ser humano perdeu muito com 0 avanço tecnológico, com o isolamento da vida das pessoas. A cabou o romantismo que existia nas relações entre as pessoas. Os jovens estão perdendo a juventude, estão se tornando adultos muito rápido.

O utros divertimentos da população em geral eram 0 teatro e 0 cinema. A partir da década de 50, o teatro entrou em decadência e Botucatu virou a capital do cinema. Aqui existiram: Companhia Teatral Studio, Metro-Goldwyn-Mayer, Universal, International, United, Warner Brothers, Paramount, agências de filmes italianas e francesas que lançavam filmes para toda a Alta Sorocabana. Os cinemas de Botucatu foram muito frequentados pela população nessa época. Havia o Paratodos (hoje Teatro Municipal), o Cassino (que pegou fogo), o Esperia (na Praça do Bosque) e o cinema do Bairro da Estação. Nos finais de semana, todas as sessões de cinema ficavam cheias.

Aos sábados e domingos, a Rua Amando enchia de pessoas: era o footing passatempo existente em diversas cidades do interior na época. As moças andavam na calçada e os moços ficavam parados na rua, olhando-as. Muitos namoros e futuros casamentos surgiram dessa prática.

A criançada naquela época tinha um fascínio grande pelo lixo, porque ali muitas vezes eles encontravam coisas que podiam ser reutilizadas. A gente ouvia o lixeiro vindo por causa do barulho que fazia na rua de paralelepípedos a carroça com roda de madeira e aro de ferro, puxada por um burro. Corríamos colocar o lixo na rua para ser levado. Naquele tempo não existia o plástico: 0 lixo era colocado em bacias, baldes e latas de azeite e 0 lixeiro despejava dentro da carroça, devolvendo o balde para ser reutilizado. Cada um ia catar a sua lata. Ninguém falava de meio ambiente, de preservação. Diziam que esse 
lixo recolhido ficava em valetas próximas ao Rio Lavapés, longe da cidade, ou então era utilizado para aterrar valas e lugares com erosão. Mas, a partir de um determinado momento, a produção de lixo passou a ser muito maior, e foi preciso construir aterros sanitários. Nós produzimos muito lixo hoje, há muito desperdício. Houve um tempo em que, apesar de fruta ser algo barato, não havia tanto consumo, e as pessoas vendiam frutas da época pela cidade. Hoje, supermercados têm distribuição de frutas e verduras à vontade, em qualquer época do ano, então, esse exagero faz com que elas sobrem - nas casas e nos supermercados - e as pessoas têm que jogá-las fora. 0 excesso de cascas de frutas e restos de verduras e legumes jogados no lixo era bem menor. Além de consumir menor quantidade de frutas da época, as pessoas também utilizavam as cascas, os talos e as folhas para 0 consumo, para fazer diversas receitas de sucos e comidas. Q uase nada era desperdiçado, utilizava-se o que se colhia.

A cidade já tinha abastecimento de luz elétrica, água e telefone. Q uando faltava água, podíamos buscar na Bica do Bispo, que era uma nascente existente dentro da residência do bispo. A princípio, ficava dentro dos portões, depois fizeram uma bica para o lado de fora, acessivel a qualquer um.

A distribuição de água ocorria principalmente no centro e nos bairros mais próximos. A água era captada de um rio, armazenada na caixa d'água da cidade e a sua distribuição era gerenciada pela Prefeitura. A partir da década de 70, a cidade começou a crescer e houve uma mudança no fornecimento de água. A população passou a povoar bairros mais distantes e começaram os racionamentos.

0 fornecimento de luz no centro também já existia. Botucatu foi uma cidade do interior privilegiada nessa época. 0 dono das indústrias Bacchi construiu uma usina hidrelétrica onde hoje é a Cascata do Véu da Noiva. Foi pioneiro no fornecimento de eletricidade produzida pela própria cidade. Nos anos 40 , foi criada a CPFL e 0 fornecimento de energia deixou de ser responsabilidade dos Bacchi. Somente as ruas do centro da cidade tinham iluminação à noite. Um funcionário acendia e apagava as luzes todos os dias, próximo das 18 
horas. Às 6 horas da manhã, ele passava outra vez, puxava a chave de luz e as apagava.

As geladeiras só começaram a aparecer na década de 50, depois da guerra, quando melhorou o serviço de fornecimento de energia. Antes disso, o leite, por exemplo, era vendido pelo leiteiro e trazido dentro de garrafas de vidro de um litro, com rolha de sabugo ou palha. Era fervido em casa, tirava-se a nata para fazer manteiga e de noite enchia-se a pia de água, tampava-se e deixava-se o leite e a manteiga dentro para conservar até 0 dia seguinte. Produtos perecíveis eram consumidos de imediato porque não tínhamos como conservar. Comidas secas eram guardadas no guarda-comidas.

Tivemos também grande evolução nos processos de comunicação. Na década de 50, o forte da comunicação era 0 telégrafo, cujo aparelho transmissor era do tamanho de uma geladeira. A comunicação era precária. 0 telefone já existia nessa época, mas para fazer uma ligação para Pardinho podia-se levar um dia inteiro. Era mais rápido ir até essa cidade a pé para dar o recado!

Para se locomover pela cidade, não havia tanta necessidade de ônibus: a locomoção era feita a pé. 0 pessoal do sítio vinha para a cidade com carroças para comprar mantimentos nas vendas. $\mathrm{Na}$ redondeza, andava-se a cavalo e no centro fazia-se tudo a pé, pois a cidade era menor. Hoje, a necessidade de transporte é maior porque as pessoas precisam se deslocar por maiores distâncias em um tempo menor, inclusive dos bairros mais afastados para o centro.

Um meio de transporte entre as cidades muito utilizado naquele tempo era 0 trem. A linha que passava por Botucatu era a Alta Sorocabana. A relação do trem com a cidade era muito estreita. Aqui era um entroncamento da Companhia Sorocabana e daqui saíam trens para todos os lugares do país. D evido a esse movimento de pessoas, negócios e mercadorias, a cidade era um polo de desenvolvimento. Botucatu perdeu muita coisa: a Sorocabana, a telefônica e as repartições públicas foram embora daqui.

Além das mudanças no ambiente e na vida das pessoas, temos hoje muitas mudanças no clima da cidade. Botucatu sempre teve fama de cidade muito fria. Quem vem de carro de São Paulo percebe que 
chegando perto de Botucatu a temperatura diminui bastante. Nas décadas de 30 a 50, faziam-se enormes fogueiras nas Festas Juninas em frente às igrejas, pois o inverno era rigoroso. Nas procissões de Corpus Christi, as ruas do centro eram enfeitadas e o povo bebia café, quentão e até pinga para esquentar porque gelava a mão, gelava tudo. Mas com o tempo o frio foi diminuindo. Alguns dizem que foi influência da construção da Represa do Rio Bonito, outros ligam o fato à grande quantidade de desmatamentos ocorrida na região. $O$ fato é que grande parte da população sente essa diferença climática.

\section{Compartilhando saberes}

Este trabalho procurou identificar, pela memória dos moradores antigos do município de Botucatu, as mudanças ambientais ocorridas, suas raízes históricas e suas consequências no momento atual, com o objetivo de contribuir para programas de Educação Ambiental na escola e fora da escola. 0 trabalho preocupou-se em valorizar essas percepções de forma que possam contribuir para 0 entendimento da crise ambiental atual, que põe em xeque o modelo de desenvolvimento econômico e político fundamentado na superioridade e no domínio do homem sobre a natureza (TOZO NI-REIS, 2004).

Para 0 enfrentamento desse modelo de desenvolvimento, fundamentado na racionalidade instrumental, Leff (2001) propõe uma nova sociologia ambiental do conhecimento que encare 0 ambiente como um sistema complexo, com "sinergias produtivas" e de um "saber ambiental" que resulte na integração de um novo discurso científico com as práticas sociais. Isso implica buscar novos paradigmas e metodologias integradores do ambiente natural e social, os quais, para esse autor, significam que:

As construções teóricas do saber ambiental não se contrastam, confirmam ou refutam com a realidade existente e na objetividade do real, mas na potencialidade de suas produçoes históricas sustentadas em processos materiais que mobilizam a construção de uma nova racionalidade. A partir de sua marginalidade 0 saber ambiental faz 
falar as verdades silenciadas, os saberes subjugados, as vozes caladas e 0 real submetidos ao poder da objetivação cientificista do mundo (LEFF, 2001)

O paradigma científico no qual se apoiou o desenvolvimento político, econômico e social da sociedade moderna nega a subjetividade do indivíduo e propõe que a ciência objetiva pode levar a verdades absolutas. Partindo-se dessa concepção de ciência, o saber dito científico se sobrepõe a qualquer tipo de saber como único e indiscutível e dá o direito de dominação da ciência a outros tipos de saberes. $\mathrm{O}$ novo paradigma que as ciências de ponta contemporâneas têm colocado, com especial destaque para a Física Quântica, nega a imparcialidade do observador e assume a sua impossibilidade de manter-se neutro no processo de interpretação da realidade (SATO; PASSO S, 2002).

Ao entendermos que a crise ambiental se dá porque nosso modelo de civilização está embasado em uma concepção insustentável da relação homem-natureza, partimos para a procura e descoberta de uma diversidade enorme de saberes calados pela dominação cultural e econômica. Ao darmos voz aos protagonistas desses saberes, nos deparamos com uma riquíssima diversidade ecológica e cultural esquecida e excluída da nossa sociedade. Foi o que vimos na história coletiva: a voz de uma parcela da população que tem muito conhecimento sobre as transformações naturais, históricas, políticas e sociais de sua cidade e até do modo de organização das sociedades no mundo. Esse conhecimento é, ao mesmo tempo, individual e coletivo, veicula sentimentos individuais profundos ao mesmo tempo que veicula visões de mundo historicamente construídas.

Vimos na história coletiva que os entrevistados relacionam as modificações ambientais, que expressam a separação homem-natureza, com o progresso social, político e tecnológico. Destaca-se nos depoimentos que a diferenciação entre meio urbano e meio rural era muito tênue na fase da economia agrícola de Botucatu. Vimos como 0 êxodo rural relaciona-se ao início da industrialização no Brasil assim 
como à consequente ocupação desordenada da cidade e ao também consequente aumento da poluição, do consumo e das diferenças sociais.

Os depoimentos nos mostram como é importante tratar as transformações socioambientais numa perspectiva histórica. Embora compreendendo a história numa abordagem leiga, até mesmo ingênua, como uma sequência de fatos e acontecimentos que se desdobram nas modificações percebidas, os moradores mais velhos da cidade de Botucatu relacionam essas transformações com transformações econômicas, políticas, sociais e culturais de um período histórico de reconhecida importância no processo de industrialização do Brasil. Nesse sentido, compreendemos que tratar as transformações socioambientais numa perspectiva histórica é muito mais do que identificar os fatos e acontecimentos que determinaram essas transformações: é analisar o contexto histórico em seus aspectos econômicos, políticos, sociais e culturais. Em coerência com o referencial teórico e metodológico já explicitado neste artigo, identifiquemos a necessidade de superar a abordagem histórica factual identificada na história da ciência com o positivismo - por meio de uma abordagem mais concreta, no sentido dialético da concreticidade: os fatos e acontecimentos históricos como síntese de múltiplas determinações.

Lembremos que a industrialização trouxe mudanças significativas para as relações sociais e, portanto, para as relações dos sujeitos sociais com 0 ambiente natural e construído. Isso significa que a compreensão do fenômeno do processo de industrialização é de fundamental importância para compreendermos a história de formação da sociedade moderna no Brasil e sua consequente relação com 0 ambiente.

Segundo Singer (1976), o início da industrialização no Brasil vai de 1885 a mais ou menos 1955. Iniciemos pela análise de que a industrialização trouxe mudanças significativas para a organização do trabalho em todo o Brasil e particularmente no estado de São Paulo. Essas transformações consolidaram uma expressiva oposição entre a burguesia industrial como classe hegemônica e a classe trabalhadora. Se, por um lado, o processo de industrialização é o cenário social, político, 
econômico e cultural da consolidação das classes sociais antagônicas, por outro, é o cenário social, político, econômico e cultural das transformações socioambientais vividas e relatadas pelos entrevistados, obviamente consideradas as condições de desenvolvimento das cidades do interior do estado de São Paulo.

Como já analisado num estudo anterior (TOZONI-REIS, 2002), que discute a vida das crianças pobres no início do processo de industrialização no Brasil, as transformações das relações de trabalho no processo de industrialização, incluindo a mecanização do campo, atingiram praticamente todos os setores da economia. Os trabalhadores do meio rural e do meio urbano sofreram modificações em suas relações de trabalho, cuja base organizativa foi o trabalho industrial. D essa forma, podemos dizer que 0 trabalho nas indústrias foi o novo modo de organização dos trabalhadores em todos os setores da economia. Essa afirmação significa que as novas relações de trabalho nas cidades e no campo têm base industrial, isto é, são relações que se definem pelo antagonismo, pois de um lado encontram-se os proprietários dos meios de produção e do outro lado encontram-se os proprietários da força de trabalho. Os primeiros compram 0 trabalho dos segundos, seja na fábrica, nos estabelecimentos comerciais ou nas fazendas. Assim, compreendemos como trabalho industrial aquele que se caracteriza por empregar trabalhadores que vendem sua própria força de trabalho, cabendo aos proprietários comprar essa força de trabalho, não necessariamente 0 trabalho industrial de trabalhadores que desenvolvem suas atividades no interior das fábricas (ENGUITA, 1989; MANACORDA, 1991).

As transformações na organização do trabalho no início do processo de industrialização que caracteriza a consolidação do capitalismo no Brasil criaram a oposição entre a classe trabalhadora e os proprietários da força de trabalho e foram acompanhadas por outro fenômeno: a população se expandiu, principalmente nas cidades, sofrendo influências dos processos migratórios. A imigração e a migração foram fenômenos de grande influência na formação da população principalmente nas cidades, nas transformações sociais e suas relações com 0 ambiente. 0 processo de industrialização e 0 
processo de urbanização no Brasil são fenômenos integrados, nos quais não cabe nenhuma relação de causa e efeito. A industrialização estimulou e foi estimulada pela urbanização, assim como o crescimento urbano estimulou e foi estimulado pela industrialização.

Essas novas relações sociais nas cidades, determinadas pelos processos de urbanização e industrialização, têm no conceito de classes seu fator articulador. As pessoas que aparecem na história coletiva construída por este estudo parecem ser de diferentes classes sociais: das famílias da burguesia, das famílias dos novos trabalhadores e das famílias dos excluídos dos processos de modernização da sociedade (ARIĖS, 1981). A escola de que falam os entrevistados é a escola que se expandiu nesse período, idealizada, defendida e organizada pela nova classe hegemônica, mas voltada também para a escolarização básica da população em geral, como forma social de preparar a população para um novo tipo de sociedade, a sociedade moderna (ENG UITA, 1989; MANACORDA, 1991). Nesse modelo de desenvolvimento, as relações de trabalho são estabelecidas entre os proprietários da força de trabalho e os proprietários dos meios de produção. Essas relações definem as classes sociais.

Além das modificações na organização do trabalho e no processo de urbanização, o período que se refere à história coletiva caracteriza-se por uma economia, capitalista, em forte expansão. Lembremos que o desenvolvimento capitalista no Brasil foi tardio, obedecendo a formas não clássicas de desenvolvimento (ANTUNES, 1988; OLIVEIRA, 1972). O processo de desenvolvimento industrial caminhou pela via colorial, conciliando novos e antigos interesses. D estaca-se, portanto, o fato de que, no Brasil, não tivemos rupturas entre 0 antigo modo de produção e o modo de produção emergente.

A grande propriedade predominava no Brasil e a economia era principalmente agroexportadora. As crises econômicas mundiais atingiram a economia brasileira e os fenômenos da urbanização e da industrialização enfraqueceram a agricultura. Por essas razões, no início do século XX os grandes proprietários rurais, cafeicultores principalmente, exigiram a intervenção governamental para que a exportação de café continuasse a gerar altos lucros: baixa de impostos, 
regularização e facilidades nos financiamentos, etc. Com essas e outras medidas definidas nos vários planos de valorização do café, a produção foi retomando seu crescimento até a crise mundial de 1929, quando uma superprodução puxou os preços para baixo. 0 consumo reduzido, a Segunda G rande G uerra (1939-1945) e as geadas acabaram exigindo a intervenção protecionista do Estado. 0 encarecimento da vida urbana beneficiou a burguesia urbano-industrial e penalizou as classes médias e o proletariado (SINGER, 1976).

Parece ser esse o contexto social, político e econômico referido pelos entrevistados na história coletiva: mais do que uma economia agrícola, a cidade prosperou com a vida urbana. A industrialização e a urbanização são, portanto, fenômenos importantes para a compreensão das modificações na vida das pessoas e no ambiente rural e urbano da cidade de Botucatu.

Sobre a industrialização podemos dizer que, em especial nas regiões Sul e Sudeste, com destaque para o estado de São Paulo, a indústria cresceu e se modernizou: em 1889 havia no país 600 indústrias que empregavam 60.000 operários; em 1907 esses números cresceram para 3.258 indústrias e 151.000 operários; e em 1920 já eram 13.336 as indústrias e 297.000 os operários (SANDRI, 1990). A pesar de possuir um reduzido parque industrial que produzia apenas bens de consumo e de caracterizar-se pela dependência tecnológica - maquinaria importada - e dependência financeira - capital externo -, esse processo de industrialização organizou-se sob a forma de grande indústria. Em 1907, 80\% do número total de operários em São Paulo e 57\% no antigo D istrito Federal trabalhavam nas indústrias de grande porte (SAND RI, 1990). O desenvolvimento da agricultura cafeicultora e o processo de urbanização criaram um mercado interno importante, ao passo que medidas protecionistas e a inflação garantiram a possibilidade de competição do produto industrial nacional com o produto industrial estrangeiro. A agricultura do algodão permitiu a implantação da indústria têxtil. A todos esses fatores soma-se a abundância de mão de obra barata e não qualificada do trabalhador brasileiro resultante do processo de urbanização. 
Sabemos que a indústria não se desenvolveu em oposição à agricultura. Os conflitos que ocorreram entre os dois setores econômicos não foram conflitos de ruptura, mas uma disputa pelo poder político e econômico entre setores de uma mesma classe social: a hegemonia econômica e política passava da burguesia rural para a burguesia urbano-industrial, diferentes setores da mesma classe proprietária dos meios de produção. Soma-se a isso o enriquecimento de alguns imigrantes no comércio e outros setores urbanos imprimindo características próprias, um pouco diferentes das características desses processos em outros países do mundo, e tem-se a formação das diferentes classes sociais no Brasil.

A expansão da população urbana, no entanto, foi lenta e gradual. No início do processo de industrialização, a maior parte da população encontrava-se no meio rural desenvolvendo uma economia de subsistência. Durante o colonato, a economia de subsistência significava $70 \%$ do custo de vida das famílias dos trabalhadores rurais pelo menos até os anos 20 havia preponderância da população rural sobre a urbana. No entanto, as cidades, principalmente no sul do país nos estados de São Paulo, Paraná, Santa Catarina e Rio G rande do Sul , cresceram de modo significativo. A urbanização também foi um dos elementos adequados à industrialização. A vida urbana começou a tomar vulto, e as suas novas necessidades foram criando categorias de trabalhadores no setor de serviços, os quais, mais tarde, junto com os trabalhadores das indústrias, tornaram-se parte importante da nova sociedade. Após a revolução de 1930, a indústria foi o setor-chave do sistema econômico e as transformações estruturais criaram as condições de expansão do modo capitalista de produção.

Nesse contexto, a grande crise econômica internacional que se agravou em 1929 trouxe reflexos nas economias de todos os países latino-americanos. No Brasil, o descontentamento dos agricultores com 0 preço do café no mercado internacional obrigou o Estado a empreender fortes medidas protecionistas, desagradando outros setores da agricultura nacional e da nascente burguesia urbano-industrial, que, para viabilizar seu projeto econômico, idealizava um sistema político mais aberto, com espaço para novas relações de poder (na verdade, 
com espaço para se ver representada hegemonicamente nessas novas relações de poder). A crise mundial de 1929, que causou a depressão econômica, reduziu o nível de troca entre os países. A industrialização extensiva nesse período atraiu algumas empresas de capital estrangeiro. O desenvolvimento industrial exigia do país investimentos para consolidar o capitalismo, mas, como o capital privado nacional não tinha forças para investir pesadamente e a longo prazo na indústria, investiu-se o capital estatal e mais tarde capital estrangeiro.

Com o desenvolvimento industrial, a agricultura assumiu um papel complementar na economia. A indústria desenvolveu-se num ritmo mais rápido do que a agricultura, do ponto de vista tecnológico, por exemplo. Na verdade, a agricultura manteve uma base técnica extremamente primitiva. Por um lado, ela foi fundamental no desenvolvimento industrial, principalmente no que diz respeito à acumulação de capital, e, por outro, a industrialização construiu 0 desenvolvimento urbano, criando grande demanda urbana por alimentos e contribuindo assim para a expansão da agricultura comercial (DEAN, 1977).

O utro aspecto essencial do tardio processo de industrialização foi a importação de tecnologia. A indústria exigia novos produtos e constantes mudanças no processo de produção. Porém, no Brasil a mudança nos processos de produção industrial queimou etapas: ao contrário do que ocorreu em outros países capitalistas, não foi preciso que 0 encarecimento da mão de obra estimulasse 0 desenvolvimento tecnológico, pois o Brasil sempre teve excesso de mão de obra significativamente barata. Além disso, o desenvolvimento tecnológico vem desde então determinando o crescimento do setor de serviços, que sempre teve grande importância na economia brasileira e que abasteceu a indústria com seus "pseudopequenos proprietários" (OLIVEIRA, 1972).

A industrialização no Brasil, portanto, caracterizou-se pela falta de um modelo econômico definido: o capitalismo industrial aqui implantado teve mais a forma de políticas pontuais de intervenção na economia do que propriamente um projeto econômico objetivo. Porém, desde o início do século $\mathrm{XX}$ a indústria brasileira foi se 
tornando um importante setor na economia nacional e os operários que nela trabalhavam formaram, direta ou indiretamente, uma nova classe numa nova perspectiva social.

Lembremos como os processos de imigração e de migração foram importantes para a compreensão das formas de organização da população urbana. Trata-se de processos sociais de caráter histórico, resultantes de fenômenos históricos e sociais, entre eles os econômicos. Aliados às transformações socioeconômicas nas áreas de origem dos imigrantes e dos migrantes, os processos migratórios foram resultado da necessidade de agilizar as atividades econômicas, principalmente a distribuição de produtos. Essa necessidade atraiu trabalhadores para os meios urbanos, ampliando a população urbana. Nota-se que a imigração foi um fator decisivo na construção da classe operária no Brasil: em 1901, dos cinquenta mil operários no estado de São Paulo, menos de dez por cento eram brasileiros; na capital, a porcentagem de trabalhadores imigrantes era por volta de cinquenta por cento; em 1906, no Rio de Janeiro, a grande maioria dos trabalhadores era composta por portugueses e espanhóis; em 1912, nas fábricas de tecido de São Paulo, apenas dezoito por cento eram brasileiros; em 1920, mais de cinquenta por cento eram imigrantes, principalmente italianos (CARO NE, 1978).

Com o fim do trabalho escravo, a força de trabalho livre formou o proletariado rural no Brasil. A cultura do café, seguida pela do açúcar, foi o principal setor em que as relações de trabalho assim se caracterizavam. Por outro lado, as relações de trabalho no meio rural ainda guardavam componentes das relações escravocratas. Os proprietários de terras estabeleceram com os novos trabalhadores rurais uma relação de seventia: a meação, a parceria, o colonato, o barracão. Tudo indica que é a essa prática de serventia que se referem os entrevistados que nos forneceram os depoimentos para a construção de nossa história coletiva sobre as transformações socioambientais da cidade de Botucatu.

No contexto da substituição da economia agrícola pela industrialização, os fazendeiros de café fizeram pressão para 0 aumento da imigração, pois o aumento da oferta de mão de obra significava a possibilidade do barateamento dos salários. No entanto, eles impunham 
aos novos trabalhadores condições insuportáveis: pagamentos irregulares, isolamento, falta de assistência médica, falta de escolas, falta de igrejas e, principalmente, o sistema de barracãa Como a imigração trouxe trabalhadores mais qualificados e mais exigentes com relação à qualidade de vida, a tendência dos imigrantes era a migração para as cidades, estabelecendo-se na indústria e no comércio. Essa tendência aparece nos relatos dos entrevistados com relação à formação da população urbana na cidade de Botucatu: a formação da Rua Curuzu pelos imigrantes como uma rua de comércio.

A década que se inicia em 1930, no entanto, foi marcada pela retração da imigração: no final dos anos trinta os brasileiros já eram maioria entre os trabalhadores industriais. A migração passou a ter, já no final dos anos 20 e sobretudo entre os anos 30 e 50, grande importância para a formação social urbana. Os processos migratórios caracterizaram-se por migrações de um meio rural para outro e migrações dos meios rurais para os meios urbanos. Elas são, em geral, consequências demográficas das mudanças técnicas de produção. A migração é, então, um processo de condicionantes históricos que diz respeito às classes sociais, que, atingidas pelas mudanças dos processos de produção, inserem-se na dinâmica social e econômica das sociedades. Esse é o sentido histórico daquilo que foi percebido pelos entrevistados e apresentado, em forma de síntese, em nossa história coletiva: a complexificação da vida urbana e suas consequentes transformações socioambientais.

Nota-se que o processo de urbanização deu-se de forma insustentável e desordenada desde 0 início do século vinte e acompanhou o desenvolvimento tecnológico da sociedade moderna. Esse modelo de sociedade é colocado pelas classes detentoras do poder econômico como única via para se atingir o desenvolvimento. A cidade concentra a produção industrial e as sobras do consumo doméstico, externalizando os custos ecológicos para seu entorno rural para abastecer necessidades crescentes de água, alimento e energia (LEFF, 2001). Externalização cujos custos ecológicos não se refletem somente em aspectos de degradação ambiental, como desmatamentos e perda de diversidade biológica, mas também no campo social, visto que 
populações expulsas do campo migram para periferias das cidades, 0 que gera sérios problemas sociais, como identificaram os moradores idosos ao comentarem as transformações ambientais em Botucatu.

O utro ponto interessante para análise expresso pelos idosos relaciona-se aos valores éticos e sociais. Valores individualistas e consumistas surgem nesses processos e as pessoas não criam uma identidade coletiva e de enraizamento (BOSI, 1987). O movimento ambientalista crítico se coloca contra a lógica de mercado individualista, mecanicista e imediatista (LOUREIRO, 2004) como forma de enfrentamento desse tipo de organização social.

0 momento atual é visto pelos entrevistados como de profunda crise. No entanto, mais do que uma situação dada, estática, vemos a crise econômica, social, ambiental, religiosa, política, moral em que vivemos com perspectivas de superação. Muitos movimentos sociais vêm surgindo e trazem novas propostas teóricas e práticas de soluções para a crise global, social e ambiental. Bosi (1987) propõe o engajamento político das classes populares como forma de enraizamento pela sua participação na coletividade; Boff (1999) propõe saber aiidar como forma de (re)ligamento, compaixão e ternura com a vida; Satto e Passos (2002) e Martinic (1985) propõem o resgate dos diferentes saberes e das diferentes culturas para que ultrapassemos as diversas fronteiras da interação eu-outro-mundo; Loureiro (2004) propõe a politização do debate ambiental pela educação ambiental crítica, transformadora e emancipatória. Diversas organizações governamentais e da sociedade civil vêm propondo uma grande mudança de paradigma através de pequenas ações locais.

Nesse sentido, a compreensão mais aprofundada das transformações ambientais que a história coletiva aqui apresentada estimula pode contribuir para a discussão mais ampla, histórica e politicamente contextualizada de diferentes formas de trabalho em Educação Ambiental na perspectiva crítica, transformadora e emancipatória. Historicizar as relações das populações urbanas e rurais com 0 ambiente em que vivem não significa identificar fatos e acontecimentos, mas interpretá-los criticamente, levando em conta os 
fatores econômicos, políticos, culturais e sociais da formação das sociedades atuais e de sua relação com 0 ambiente.

\section{Referências}

ANTUNES, Ricardo. Classe qpeánia, sindicatos e partido mo Brasil. São Paulo: Cortez, 1988.

ARIÈ S, Philippe. Históna soial da ciança edafamília Rio de Janeiro: Zahar, 1981.

BOFF, Leonardo. Saber Cuidar. ética do humano - compaixão pela terra. Petrópolis: Vozes, 1999.

BOSI, Ecléa. Cultura e desenraizamento. In: BO SI, Alfredo (O rg.). Cultura brasilera: temas e situações. São Paulo: Ática, 1987. p. 16-41.

CARONE, Edgard. A Repúdica V dha: instituições e classes sociais (1889-1930). Rio de Janeiro; São Paulo: DIFEL, 1978.

CARVALHO, Isabel Cristina de Moura. A invenãa eđóóga narrativas e trajetórias da Educação Ambiental no Brasil. 2. ed. Porto Alegre: Editora da UFRGS, 2002.

DEAN, Warren. A industrialização durante a República Velha. In: Fausto, Boris. (D ir.). História Geral da Civilização Brasileira. São Paulo: DIFE L, 1977. (Tomo 3, v. 1).

ENGUITA, Mariano Femández. A face culta da ๕cda. Porto Alegre: Artes Médicas, 1989.

FERREIRA, Marieta de Moraes (Org.). Históna arl e miltidsaipinanidade Rio de Janeiro: Diadorim, 1994.

FREIRE, Paulo. Educacãoemudança 21. ed. São Paulo: Paz e Terra, 1979.

GRÜN, Mauro. Ética e eduracãa anhietal: a conexão necessária. Campinas: Papinus, 1996.

LEFF, Ennique. Saber ambietal: sustentabilidade, racionalidade, complexidade, poder. 2. ed. Petrópolis: Vozes, 2001.

LO URE IRO, Carlos Frederico B. Trajéćia e fundamettos da Eduração Ambietal. São Paulo: Cortez, 2004.

MANACO RDA, Mario Alghiero. Marx ea Peelaggaja Modama. São Paulo: Cortez, 1991.

MARTINIC, Sergio. Saber popular y identidad. In:

Améica Latina Buenos Aires: Busqueda, 1985. p. $13 \overline{9}-1 \overline{1} 2$. . Saber pqular y educadónen

ME IHY, José Carlos Sebe Bom. Manual dehistóia aal. São Paulo: Edições Loyola, 1996. 
MINAY O , Maria Cecília de Souza. Ciência, técnica e arte: o desafio da pesquisa social. In: ___ (Org.). Pesquisa saial: teoria, método e criatividade. 9. ed. Petrópolis: Vozes, 1994. p. 9-29.

OLIVEIRA, Francisco de. A economa brasileira: crítica à razão dualista. São Paulo: Editora Brasileira de Ciências, 1972. (Estudos CEBRAP 2).

REIGOTA, Marcos Antonio dos Santos. Eødogstas Santa Cruz do Sul: EUNISC, 1999.

SAND RI, Adriano. Os trabalhadores e o moimento sindical no Brasil. Belo Horizonte: GEFASI, 1990.

SATO, Michèle; PASSO S, Luiz A. Biorregionalismo: identidade histórica e caminhos para a cidadania. In: In: CASTRO Ronaldo Souza; LAYRARG UE S, Philippe Pomier; LO URE IRO, Carlos Frederico B. (O rg.). Educação Anbiental: repensando o espaço da cidadania. 2. ed. São Paulo: Cortez, 2002. p. 221-252.

SAVIANI, Dermeval. Sobre a natureza e a especificidade da educação. In:

Pedagogia históicońtica: primeiras aproximações. 4. ed. São Paulo: Cortez, 1994. p. $\overline{2} \overline{1}$ 35.

SING ER, Paul. Interpretando o Brasil: uma experiência histórica de desenvolvimento. In: BUARQ UE DE HOLANDA, Sérgio (D ir.). Históia geal da đivilização brasileira São Paulo: FITEL, 1976. (Tomo 3, v. 4).

TOZO NI-REIS, Marília Freitas de Campos. Infânna, exdaepdbreza fiç̧ão e realidade. Campinas: Autores Associados, 2002. $\overline{2} \overline{0} \overline{4}$.

. Eduração ambiental: natureza, razão e história. Campinas: Autores Associados, VIDÁGUA. Disponível em: <http:/ / www.vidagua.org.br>. Acesso em: 15 set. 2004.

VIERTLER, Renate Brigitte. Métodos antropológicos como ferramenta para estudos em etnobiologia e etnoecologia. In: AMO ROZO, Maria Christina de M.; MING, Lin Chau; SILVA, Sandra Pereira (Ed.). Métodos de cdéa e análise de dados em endaidoga, enoedogia edisiplinascomdatas Rio Claro: UNESP, 2002. p. 11-29.

Artigo: recebido em 07/ 08/ 2008 - aprovado em 17/ 12/ 2008 